\title{
Comparison of the predictive performance of the BIG, TRISS, and PS09 score in an adult trauma population derived from multiple international trauma registries
}

Thomas Brockamp ${ }^{1 *}$, Marc Maegele ${ }^{1,10}$, Christine Gaarder 2,10, J Carel Goslings ${ }^{4,10}$, Mitchell J Cohen 5,10, Rolf Lefering ${ }^{1}$, Pieter Joosse ${ }^{4}$, Paal A Naess ${ }^{2,10}$, Nils O Skaga ${ }^{3}$, Tahnee Groat ${ }^{5}$, Simon Eaglestone ${ }^{9,10}$, Matthew A Borgman ${ }^{7}$, Philip C Spinella ${ }^{8}$, Martin A Schreiber ${ }^{6}$ and Karim Brohi ${ }^{9,10}$

\begin{abstract}
Background: The BIG score (Admission base deficit (B), International normalized ratio (I), and Glasgow Coma Scale (G)) has been shown to predict mortality on admission in pediatric trauma patients. The objective of this study was to assess its performance in predicting mortality in an adult trauma population, and to compare it with the existing Trauma and Injury Severity Score (TRISS) and probability of survival (PS09) score.

Materials and methods: A retrospective analysis using data collected between 2005 and 2010 from seven trauma centers and registries in Europe and the United States of America was performed. We compared the BIG score with TRISS and PSO9 scores in a population of blunt and penetrating trauma patients. We then assessed the discrimination ability of all scores via receiver operating characteristic (ROC) curves and compared the expected mortality rate (precision) of all scores with the observed mortality rate.

Results: In total, 12,206 datasets were retrieved to validate the BIG score. The mean ISS was $15 \pm 11$, and the mean 30-day mortality rate was $4.8 \%$. With an AUROC of 0.892 ( $95 \%$ confidence interval (CI): 0.879 to 0.906 ), the BIG score performed well in an adult population. TRISS had an area under ROC (AUROC) of 0.922 (0.913 to 0.932) and the PSO9 score of 0.825 (0.915 to 0.934). On a penetrating-trauma population, the BIG score had an AUROC result of 0.920 (0.898 to 0.942 ) compared with the PSO9 score (AUROC of $0.921 ; 0.902$ to 0.939 ) and TRISS $(0.929 ; 0.912$ to 0.947 ).

Conclusions: The BIG score is a good predictor of mortality in the adult trauma population. It performed well compared with TRISS and the PSO9 score, although it has significantly less discriminative ability. In a penetratingtrauma population, the BIG score performed better than in a population with blunt trauma. The BIG score has the advantage of being available shortly after admission and may be used to predict clinical prognosis or as a research tool to risk stratify trauma patients into clinical trials.
\end{abstract}

\section{Background}

The early prediction of mortality in trauma patients is challenging but has important potential benefits. The utility of existing mortality-prediction tools is confined to retrospective applications such as quality assessment,

\footnotetext{
* Correspondence: tbrockamp@gmail.com

'Department of Traumatology and Orthopedic Surgery, Cologne Merheim Medical Center (CMMC), University of Witten/ Herdecke, Ostmerheimer Str. 200, D-51109 Cologne, Germany

Full list of author information is available at the end of the article
}

as they rely on variables not available in the early phases of care (such as the injury severity score). Accurate early prediction of the risk of death might have the potential to inform triage decisions, inform treatment, or stratify patients for further care. In particular, it would be attractive as an entry criterion for clinical trials to match an intervention to an appropriate at-risk population.

The BIG score (Admission base deficit (B), International normalized ratio (I), and Glasgow Coma Scale (G)) is a mortality-predicting score that has been shown to 
predict mortality accurately on admission in a cohort of pediatric trauma patients from a military trauma system. The BIG score performed better than other pediatric trauma scoring systems and was validated in a separate pediatric population with similar accuracy [1]. The BIG score has not been applied to adults, and its accuracy has not been compared with that of existing trauma mortality-prediction tools.

The first aim of this study was to assess whether the BIG score can predict mortality in an adult trauma population and to compare the predictive ability of the BIG score with the commonly used mortality-predicting Trauma and Injury Severity Score (TRISS; Trauma Score and Injury Severity Score (ISS) based on the ISS and the Revised Trauma Score (RTS), age and injury mechanism) and PS09 (Probability of Survival; model 09 based on ISS, GCS, age, gender and intubation) score [1-5].

A second aim was to evaluate and compare the ability to predict mortality of all scores on different subgroups.

\section{Results}

In total, 12,206 patients were included in the study. Of those, 4,949 patients were included by civilian trauma centers, and 7,257 (59\%) patients were included by military trauma centers (Table 1).

\section{Demographic data}

Table 2 provides an overview of demographic and baseline physiological data of each database. Data are presented as means or as percentages. The mean ISS was $15 \pm 11$ with a 30 -day mortality rate of $4.8 \%$. Table 3 presents all variables associated with mortality. In total, 588 (4.8\%) patients died. Survivors were younger (33.2 versus 50.4 years) and were more likely to sustain penetrating trauma (47.5\% versus $26.0 \%)$. Nonsurvivors had a significantly higher ISS (33 versus 14; $P<0.001$ ), a worse mean base excess $(-6.9$ versus $-1.9 ; P<0.001)$, and a lower GCS (7 versus $14 ; P<0.001)$.

\section{Quality criteria}

Table 4 characterizes quality criteria for all scores compared. The table presents the discrimination and precision ability of the BIG, TRISS, and PS09 scores for all patients as well as for a blunt- and penetrating-trauma population. The AUROCof the BIG score and the TRISS score are significantly different $(P<0.001)$. The difference between the TRISS and PS09 scores is not statistically significant $(P=0.32)$ in the combined dataset.

The expected mortality rate (precision) of the BIG score, PS09 score, and TRISS was compared with the observed mortality rate. In Table 4, the observed mortality of all patients is set by $4.8 \%$. The expected mortality calculated for the BIG score is $4.8 \%$, whereas the expected mortality of the TRISS and PS09 scores are $6.6 \%$ and $7.9 \%$, respectively.

\section{Blunt trauma}

Comparing only patients who sustained blunt trauma ( $n=6,540)$, our analysis shows that the overall accuracy of the PS09 score had an AUROC of 0.921 (95\% CI, 0.911 to 0.932 ), the TRISS score of 0.917 (95\% CI, 0.906 to 0.928 ), and the BIG score had an AUROC of 0.876 (95\% CI, 0.859 to 0.892 ). The difference between AUROC of the BIG score and the TRISS score is significant $(P<0.001)$. The difference between the TRISS and PS09 score is not statistically significant $(P=0.24)$ in the blunt dataset.

\section{Penetrating trauma}

In patients with penetrating trauma $(n=5,666)$, the BIG score $(0.920$; $95 \% \mathrm{CI}, 0.898$ to 0.942$)$ performed comparably to the PS09 score $(0.921 ; 95 \%$ CI, 0.902 to 0.939). The TRISS score had an AUROC of 0.929 (95\% CI, 0.912 to 0.947). The difference between AUROC results in the penetrating group was not significant (all $P>0.16)$.

Table 1 Characteristics of all databases.

\begin{tabular}{|c|c|c|c|c|c|c|c|}
\hline \multirow[t]{2}{*}{ Database } & 1 & 2 & 3 & 4 & 5 & 6 & 7 \\
\hline & Amsterdam & London & Oregon & Oslo & San Francisco & TR-DGU & JTTR \\
\hline Site & $\begin{array}{c}\text { Academic Medical } \\
\text { Center } \\
\text { Amsterdam, } \\
\text { Netherlands }\end{array}$ & $\begin{array}{l}\text { Royal London } \\
\text { Hospital London, } \\
\text { United Kingdom }\end{array}$ & $\begin{array}{c}\text { Health \& Science } \\
\text { University } \\
\text { Oregon, Portland } \\
\text { US }\end{array}$ & $\begin{array}{c}\text { University } \\
\text { Hospital } \\
\text { Ulleval Oslo, } \\
\text { Norway }\end{array}$ & $\begin{array}{l}\text { General Hospital } \\
\text { San Francisco, } \\
\text { California US }\end{array}$ & $\begin{array}{l}\text { TraumaRegister } \\
\text { DGU }\end{array}$ & $\begin{array}{c}\text { US Army Institute of } \\
\text { Surgical Research, San } \\
\text { Antonio, Texas US }\end{array}$ \\
\hline $\begin{array}{l}\text { Year of } \\
\text { data } \\
\text { collection }\end{array}$ & 2005-2010 & $2005-2010$ & 2008-2010 & 2008-2010 & $2005-2010$ & $2005-2010$ & $2005-2010$ \\
\hline $\begin{array}{l}\text { Civilian or } \\
\text { military } \\
\text { data }\end{array}$ & Civilian & Civilian & Civilian & Civilian & Civilian & Civilian & Military \\
\hline $\begin{array}{l}\text { Number } \\
\text { of } \\
\text { patients }\end{array}$ & 609 & 1,483 & 142 & 544 & 247 & 1,924 & 7257 \\
\hline
\end{tabular}

All seven databases are shown together with the number of patient data contributed by each site. $n$, total number of patients. 
Table 2 Demographic data of all sites compared.

\begin{tabular}{|c|c|c|c|c|c|c|c|c|c|}
\hline Variable & & $\begin{array}{c}\text { Total } \\
(N=12,206)\end{array}$ & $\begin{array}{l}\text { Amsterdam } \\
(n=609)\end{array}$ & $\begin{array}{c}\text { London } \\
(n=1,483)\end{array}$ & $\begin{array}{c}\text { Oregon } \\
(n=142)\end{array}$ & $\begin{array}{c}\text { Oslo } \\
(n=544)\end{array}$ & $\begin{array}{c}\text { San Francisco } \\
(n=247)\end{array}$ & $\begin{array}{c}\text { TRDGU } \\
(n=1,924)\end{array}$ & $\begin{array}{c}\text { JTTR } \\
(n=7,257) \\
\end{array}$ \\
\hline Age (years) & $\begin{array}{l}\text { Mean } \\
\pm \mathrm{SD}\end{array}$ & $34 \pm 16$ & $44 \pm 18$ & $39 \pm 17$ & $52 \pm 18$ & $44 \pm 18$ & $42 \pm 19$ & $46 \pm 19$ & $28 \pm 11$ \\
\hline Male & n (\%) & 10,784 (88.3) & $432(70.9)$ & $1201(63.8)$ & $108(76.1)$ & $405(74.4)$ & $202(81.8)$ & $1432(74.4)$ & 7004 (96.5) \\
\hline Penetrating trauma & n (\%) & $5666(46.4)$ & $41(6.7)$ & $216(14.6)$ & $15(10.6)$ & $36(6.6)$ & $81(32.8)$ & $98(5.1)$ & $5179(71.4)$ \\
\hline $\begin{array}{l}\text { Intubated (on } \\
\text { scene) }\end{array}$ & n (\%) & $1688(13.9)$ & $72(11.8)$ & NA & NA & $86(15.8)$ & $232(93.9)$ & $1057(55.0)$ & $232(3.2)$ \\
\hline $\begin{array}{l}\text { Systolic Blood } \\
\text { Pressure (mmHg) }\end{array}$ & $\begin{array}{l}\text { Mean } \\
\pm S D\end{array}$ & $128 \pm 25$ & $137 \pm 27$ & $129 \pm 29$ & $138 \pm 32$ & $133 \pm 29$ & $127 \pm 39$ & $124 \pm 30$ & $128 \pm 21$ \\
\hline Heart rate (bpm) & $\begin{array}{l}\text { Mean } \\
\pm S D\end{array}$ & $93 \pm 22$ & $87 \pm 19$ & $91 \pm 25$ & $92 \pm 24$ & $89 \pm 19$ & $98 \pm 28$ & $89 \pm 21$ & $94 \pm 22$ \\
\hline $\begin{array}{l}\text { Respiratory rate } \\
\text { (pm) }\end{array}$ & $\begin{array}{l}\text { Mean } \\
\pm S D\end{array}$ & $19 \pm 7$ & $17 \pm 5$ & $19 \pm 7$ & $19 \pm 6$ & $19 \pm 7$ & $21 \pm 6$ & $15 \pm 6$ & $20 \pm 6$ \\
\hline INR & $\begin{array}{l}\text { Mean } \\
\pm S D\end{array}$ & $1.2 \pm 0.5$ & $1.0 \pm 0.4$ & $1.1 \pm 0.3$ & $1.3 \pm 0.5$ & $1.1 \pm 0.3$ & $1.2 \pm 0.4$ & $1.2 \pm 0.8$ & $1.2 \pm 0.4$ \\
\hline $\begin{array}{c}\text { Base excess (mmol/ } \\
\text { l) }\end{array}$ & $\begin{array}{l}\text { Mean } \\
\pm S D\end{array}$ & $2.2 \pm 4.0$ & $2.2 \pm 3.7$ & $2.2 \pm 4.4$ & $2.7 \pm 3.5$ & $-2.1 \pm 3.1$ & $6.6 \pm 5.2$ & $3.2 \pm 4.3$ & $-1.7 \pm 3.8$ \\
\hline $\begin{array}{l}\text { Glasgow Coma } \\
\text { Scale (total) }\end{array}$ & $\begin{array}{l}\text { Mean } \\
\pm S D\end{array}$ & $13 \pm 3$ & $13 \pm 4$ & $13 \pm 4$ & $13 \pm 3$ & $14 \pm 3$ & $9 \pm 5$ & $11 \pm 5$ & $14 \pm 3$ \\
\hline $\begin{array}{l}\text { Injury Severity Score } \\
\text { (ISS) }\end{array}$ & $\begin{array}{l}\text { Mean } \\
\pm S D\end{array}$ & $15 \pm 11$ & $15 \pm 11$ & $18 \pm 11$ & $24 \pm 12$ & $16 \pm 11$ & $28 \pm 15$ & $24 \pm 14$ & $12 \pm 9$ \\
\hline $\begin{array}{l}\text { Lengh of stay on } \\
\text { ICU (days) }\end{array}$ & $\begin{array}{l}\text { Mean } \\
\pm S D\end{array}$ & $6.2 \pm 10.1$ & $1.6 \pm 4.1$ & $2.9 \pm 6.7$ & $8.3 \pm 9.3$ & $3.8 \pm 5.9$ & $9.1 \pm 8.9$ & $10.4 \pm 12.7$ & NA \\
\hline $\begin{array}{l}\text { Lengh of stay in } \\
\text { hospital (days) }\end{array}$ & $\begin{array}{l}\text { Mean } \\
\pm S D\end{array}$ & $17.8 \pm 22$ & $9.9 \pm 15.4$ & $18.1 \pm 25.3$ & $16.1 \pm 15.7$ & $6.6 \pm 8.1$ & $21.1 \pm 27.1$ & $22.9 \pm 20.8$ & NA \\
\hline $\begin{array}{c}\text { Mortality within } 30 \\
\text { days }\end{array}$ & n (\%) & $588(4.8)$ & $30(4.9)$ & $80(5.4)$ & $9(6.3)$ & $22(3.0)$ & $71(28.7)$ & $242(12.6)$ & 139 (1.9) \\
\hline
\end{tabular}

Data are presented as mean and standard deviation (SD) or as percentage. ISS, Injury Severity Score; ICU, Intensive Care Unit; TRDGU, TraumaRegister DGU ${ }^{\circledR}$ of the German Trauma Society; JTTR, Joint Theater Trauma Registry; INR, International Normalized Ratio.

\section{Military and civilian data}

On a military dataset $(n=7,257)$, the BIG score had an AUROC of 0.929 (95\% CI, 0.909 to 0.949), and the PS09 score had an AUROC of 0.922 (95\% CI, 0.904 to 0.940 ) and TRISS of 0.915 (95\% CI, 0.891 to 0.939) (all $P>0.31)$. On a civilian dataset $(n=4949)$, the PS09 score had a similar AUROC $(0.901 ; 95 \% \mathrm{CI}, 0.887$ to
$0.914)$ to the TRISS $(0.896 ; 95 \% \mathrm{CI}, 0.882$ to 0.909 ; $P=0.24)$. The AUROC of the BIG score $(0.849 ; 95 \% \mathrm{CI}$, 0.830 to 0.868$)$ was significantly lower $(P<0.001)$ (Table 5).

Figure 1 depicts the AUROCs for the BIG, TRISS, and PS09 scores on all blunt and penetrating trauma patients combined.

Table 3 Variables associated with mortality.

\begin{tabular}{|c|c|c|c|c|}
\hline Variable & & Survivor ( $n=11618$ ) & Non-survivor $(n=588)$ & $\mathrm{p}$-value \\
\hline Age & Mean \pm SD & $33.2 \pm 15.2$ & $50.4 \pm 22.9$ & $<0.001$ \\
\hline Male & $\%$ & 89.1 & 74.3 & $<0.001$ \\
\hline Penetrating trauma & $\%$ & 47.5 & 26.0 & $<0.001$ \\
\hline Intubated (on scene) & $\%$ & 11.9 & 55.8 & $<0.001$ \\
\hline Systolic Blood Pressure $(\mathrm{mmHg})$ & Mean \pm SD & $129 \pm 22$ & $96 \pm 35$ & $<0.001$ \\
\hline Heart rate (bpm) & Mean \pm SD & $93 \pm 22$ & $96 \pm 35$ & 0.032 \\
\hline Respiratory rate (pm) & Mean \pm SD & $19 \pm 6$ & $16 \pm 10$ & $<0.001$ \\
\hline INR & Mean \pm SD & $1.1 \pm 0.3$ & $1.7 \pm 1.6$ & $<0.001$ \\
\hline Base excess mmol/l & Mean \pm SD & $1.9 \pm 3.7$ & $6.9 \pm 6.5$ & $<0.001$ \\
\hline Glasgow Coma Scale (total) & Mean \pm SD & $14 \pm 3$ & $7 \pm 5$ & $<0.001$ \\
\hline Injury Severity Score & Mean \pm SD & $14 \pm 10$ & $33 \pm 16$ & $<0.001$ \\
\hline Lengh of stay on ICU (days) & Mean \pm SD & $6.4 \pm 10.4$ & $4.5 \pm 5.4$ & $<0.001$ \\
\hline Lengh of stay in hospital (days) & Mean \pm SD & $19.1 \pm 22.2$ & $5.7 \pm 11$ & $<0.001$ \\
\hline
\end{tabular}


Table 4 Quality criteria for all scores compared.

\begin{tabular}{|c|c|c|c|}
\hline & BIG score & TRISS & PS09 score \\
\hline \multicolumn{4}{|l|}{ Discrimination } \\
\hline AUROC curve $(95 \% \mathrm{Cl})$ All patients $(n=12206)$ & $0.892(0.879-0.906)$ & $0.922(0.913-0.932)$ & $0.925(0.915-0.934)$ \\
\hline AUROC curve $(95 \% \mathrm{Cl})$ Blunt trauma $(n=6540)$ & $0.876(0.859-0.892)$ & $0.917(0.906-0.928)$ & $0.921(0.911-0.932)$ \\
\hline AUROC curve $(95 \% \mathrm{Cl})$ Penetrating trauma $(n=5666)$ & $0.920(0.898-0.942)$ & $0.929(0.912-0.947)$ & $0.921(0.902-0.939)$ \\
\hline \multicolumn{4}{|l|}{ Precision } \\
\hline \multicolumn{4}{|l|}{ All patients } \\
\hline Predicted Mortality (\%) & 4.8 & 6.6 & 7.9 \\
\hline Observed Mortality (\%; 95\% Cl) & & $4.8(4.4-5.2)$ & \\
\hline \multicolumn{4}{|l|}{ Blunt Trauma } \\
\hline Predicted Mortality (\%) & 5.5 & 9.6 & 11.9 \\
\hline Observed Mortality (\%; 95\% Cl) & & $6.7(6.1-7.3)$ & \\
\hline \multicolumn{4}{|l|}{ Penetrating Trauma } \\
\hline Predicted Mortality (\%) & 4.0 & 3.2 & 3.4 \\
\hline Observed Mortality (\%; 95\% Cl) & & $2.7(2.3-3.1)$ & \\
\hline
\end{tabular}

Quality criteria for all scores on all data $(n=12,206)$, on all blunt $(n=6,540)$ and penetrating $(n=5,666)$ trauma patients. Data are presented as AUROC (Area under receiver operating characteristic curve) together with a 95\% Confidence Interval (Cl).

\section{Discussion}

For the first time, the performance of the BIG score was analyzed on an adult trauma population. Data from civilian and military trauma centers and registries with a representative trauma population of blunt and penetrating trauma were used for the current analysis. When all scores were tested on the whole dataset, the BIG score performed well in predicting mortality in the adult trauma population. Unlike complex scoring systems, the BIG score can be used directly on admission of a trauma patient, because it uses variables that are rapidly available for assessing severity of illness and predicting mortality. Time-consuming parameters like the ISS are not included within the BIG score. Hence, the BIG score might be used for trauma trials in which mortality is the intended primary outcome parameter.

In the present analysis, the BIG score was shown to perform well in predicting mortality in the penetratingtrauma population versus the blunt-trauma population. The TRISS and the PS09 scores slightly overpredicted mortality in all subgroups. The BIG score overpredicted mortality only in the penetrating-trauma group. In addition, the mortality prediction of the BIG score was more accurate on military trauma data than on civilian data. This might be due to its composition, as the BIG score includes parameters highly reflecting the two major causes of acute death from trauma (for example, brain injury and uncontrolled hemorrhage [1,16-18]). In assessing the epidemiology of trauma death, Sauaia and coworkers [19] identified central nervous system (CNS) injuries to represent the most frequent cause of death (42\%), followed by exsanguination (39\%). The BIG score reflects these observations by including INR and GCS in the calculation. The INR provides information about the hemocoagulative status of the patient [17,20,21], whereas the GCS is used as a surrogate marker for the level of consciousness and to estimate its severity, due to either traumatic brain injury (TBI) or severe hypoperfusion [22-24]. However, the GCS was recently challenged, and the role as a tool to reflect the mental status of a trauma patient is widely discussed [25].

The third parameter of the BIG score, base deficit (BD), was shown to be a valuable indicator of shock, abdominal injury, fluid requirements, efficacy of resuscitation, and a predictor of mortality after trauma [26-31].

In the past, several scoring systems and algorithms have been developed to predict mortality in the trauma population. The one most closely related to the BIG score is the Emergency Trauma Score (EMTRAS), developed by Raum and colleagues [32] from data derived from the TraumaRegister DGU. This score includes similar components to the BIG score, including

Table 5 Military data vs.

\begin{tabular}{cccc}
\hline & BIG score & TRISS & PS09 score \\
\hline Discrimination & & & \\
\hline AUROC curve $(95 \%$ Cl) Military data $(n=7257)$ & $0.929(0.909-0.949)$ & $0.915(0.891-0.939)$ & $0.922(0.904-0.940)$ \\
AUROC curve $(95 \%$ Cl) Civilian data $(n=4949)$ & $0.849(0.830-0.868)$ & $0.896(0.882-0.909)$ & $0.901(0.887-0.914)$ \\
\hline
\end{tabular}

Civilian data. AUROC results of all compared scores on all military and on all civilian data. 


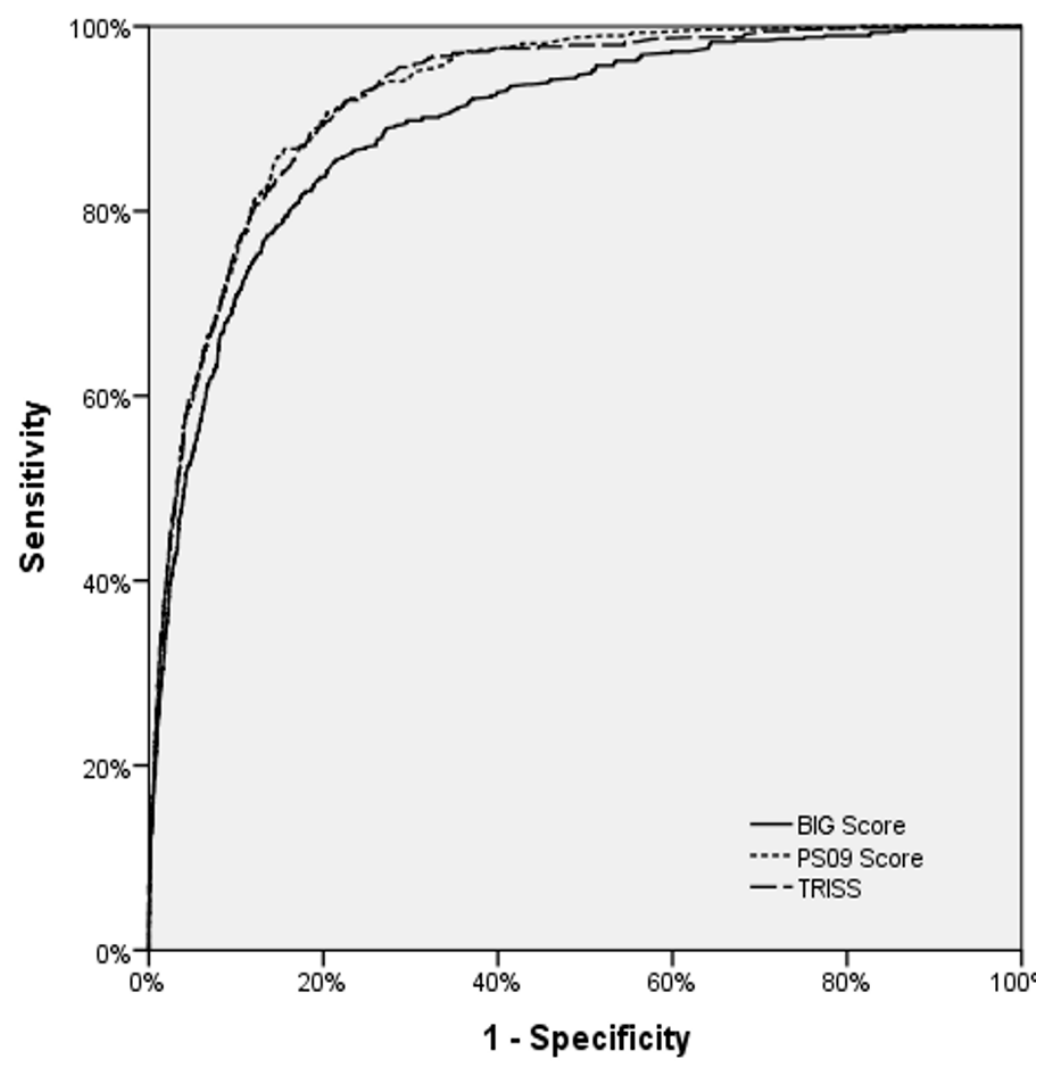

Figure 1 Receiver operating characteristic (ROC) curves for the BIG, TRISS and PS09 score.

GCS, base excess (BE), and prothrombin time (PT), as well as age. When this score was compared with the Revised Trauma Score (RTS), ISS, NISS, and TRISS scores with regard to mortality after trauma, the EMTRAS was superior. However, the EMTRAS was developed and validated on one single and retrospective database and therefore has not been validated externally or prospectively [32]. Perel and co-workers [33] recently developed a prognostic model for early death in patients with traumatic bleeding on a dataset from the Clinical Randomisation of an Antifibrinolytic in Significant Haemorrhage (CRASH-2) trial and validated the score on 14,220 selected trauma patients from the Trauma Audit and Research Network (TARN). Glasgow coma scale score, age, and systolic blood pressure were the strongest predictors of mortality. A chart was constructed to provide the probability of death at the point-of-care. Future research must evaluate whether the use of this prognostic model in clinical practice has an effect on the management and outcomes of trauma patients [33].

Most other scoring systems and algorithms to predict mortality in the trauma population on admission are limited because of their complexity and the high number of variables included for calculation. With this, the
Trauma Injury Severity Score (TRISS), for example, offers a standard approach for evaluating outcome of trauma care [2]. Similar to the TRISS, the PS09 score uses a combination of anatomic and physiological parameters. However, information on the entire and complete injury pattern is usually difficult to obtain in the acute phase of Emergency Department (ED) care and requires potentially time-consuming imaging technology. Limitations of both scores are multiple and widely discussed in the literature $[2,9,10]$. Of note, it also takes trained personnel significant time to review charts and calculate complex scores, so that the clinical use of these approaches has to be questioned.

Limitations of the present study are the same that are inherent in retrospective reviews using registry data. To generate the dataset for the present analysis, a number of patients had to be excluded as a result of missing data in the contributing registries, resulting in a selection bias of patients. Only patients with complete datasets were included in the study. In a subgroup analysis, we excluded patients with minor injuries (ISS $<4$ ), which reduced the dataset by about $20 \%$. These excluded patients are most likely survivors. Trauma mortality scores must be evaluated on a trauma population with a 
certain amount of injury severity to predict mortality accurately. On a trauma population without an ISS limitation, we proved that all three scores had slightly better AUROC results, because outcome prediction is easy in the group of patients with minor injuries.

The fact that one registry (San Francisco) obviously contributed more severely injured patients with impaired outcome into the joint dataset might also have biased the results. A similar effect may have been related to the contribution of more penetrating-trauma patients derived from the military database.

The BIG score waives the need for anatomic classifications and physiologic parameters, like systolic blood pressure, heart rate, or respiratory rate. The GCS is a simple clinical assessment, whereas BE and INR can easily and quickly be obtained from point-of-care devices in the ED setting. These results are usually known within minutes of ED arrival. The BIG score does not require any variables that are not readily available in the acute phase of injury care (for example, ISS, NISS). Therefore, we think that the BIG score can be used to identify trauma patients at risk. However, the BIG score was shown to predict mortality accurately in an adult trauma population, and it may be used to determine inclusion criteria for prospective acute care research studies.

\section{Conclusions}

Our results show that the BIG score, initially developed and validated in the pediatric trauma population, can also predict mortality in the adult trauma population. The BIG score performs well compared with complex scoring systems like the TRISS and PS09 scores, although it has significantly less discriminative ability. The score was shown to perform superiorly in the penetrating trauma-population and on a military dataset, which could make it a useful system in combat casualties, for whom time and resources are limited. In addition, the BIG score can be used independent of injury severity, and it can be used to determine inclusion criteria for prospective acute care research studies.

\section{Materials and methods Data collection}

A data-collection template was developed to collect all needed parameters from the participating sites. All primary admitted trauma-team activation patients aged 18 years or older during the period 2005 to 2010, inclusive, were eligible. Only patients with available and complete datasets for the calculation of the analyzed scoring systems (BIG, TRISS, and PS09) were included in the study $(n=15,730)$. In a second step, only patients with an ISS $\geq 4$ were considered. This requires at least an AIS 2 type of injury and excludes all minor injuries. Finally, data from 12,206 patients from one military and six civilian trauma centers and registries in Europe and the United States were collected and retrospectively analyzed. We used 30-day mortality as the primary outcome parameter of our analysis. We then compared the BIG score against the TRISS and PS09 score on a representative population of trauma patients. Subgroup analysis only on patients with blunt or penetrating trauma was additionally done.

\section{Trauma centers and registries}

Data were collected from four trauma centers participating in the International Trauma Research Network (INTRN; Amsterdam, Oslo, London, San Francisco), from the German TraumaRegister DGU (TR-DGU) and also from two participating registries in the United States (Joint Theater Trauma Registry (JTTR) and the Trauma Registry of the Oregon Health \& Science University, Portland, OR). All participating sites are level-1 trauma centers.

\section{INTRN}

The International Trauma Research Network (INTRN) is a formal academic network of high-volume trauma centers across Europe and the United States. The group was formed in 2009 and has grown strategically, developing fundamental, translational, and clinical research programs that span the complete breadth of trauma disciplines [6,7].

\section{TraumaRegister DGU}

The TraumaRegister DGU (TR-DGU) is a prospective multicenter database with standardized documentation of patients with severe trauma and thus requiring intensive care. This registry comprises detailed information on demographics and clinical and laboratory data. Data from the TraumaRegister DGU include patients from about 108 trauma units around Germany [8].

\section{OHSU Trauma Registry}

The Oregon Health and Science University (OHSU) Trauma Registry contains information from more than 45,000 patients treated since 1985 . The registry contains detailed information for each patient concerning prehospital, ED, and in-hospital care. All research projects are approved by an Institutional Review Board (IRB).

\section{JTTR}

The Joint Theatre Trauma Registry (JTTR) was established by the Department of Defense to collect comprehensive data on all personnel, military and civilian, admitted to military treatment facilities within Iraq and Afghanistan. It is maintained at the US Army Institute of Surgical Research in San Antonio, Texas, USA. 
Data are handled anonymously, and case identification is possible only through the participating hospital.

\section{Trauma scores}

For our analysis, we compared the original pediatric BIG score with the commonly used TRISS and PS09 scores $[1,2,9]$. In a second approach, we tested the mortality prediction of the BIG score on our blunt-trauma and separately on our penetrating-trauma patients and compared the score again with the TRISS and the PS09 scores (Table 6).

\section{The BIG score}

The pediatric BIG score is a mortality-predicting score for children with traumatic injuries. It was developed by Borgman and colleagues in 2011. They retrospectively analyzed data from 2002 to 2009 and found that admission base deficit (B), international normalized ratio (I), and Glasgow Coma Scale (G) were independently associated with mortality. The variables were combined into the pediatric BIG score (base deficit $+(2.5 \times$ international normalized ratio) + (15 Glasgow Coma Scale) $)$. This equation can then be implemented into a mortalitypredicting formula: predicted mortality $=1 /\left(1+\mathrm{e}^{-\mathrm{x}}\right)$, where $x=0.2 \times$ (BIG score) -5.208 . A BIG score of $<12$ points suggests a mortality of $<5 \%$, whereas a cut-off of $>26$ points corresponds to a mortality of $>50 \%$. The BIG score can be performed rapidly on admission to evaluate severity of illness and to predict mortality in children [1].

\section{The TRISS method}

Physiological and anatomic data are included in the Trauma Injury Severity Score (TRISS) that was published in 1987 by Boyd and colleagues [2] based on a North American population. Since then, the estimation of prognosis is also discussed critically, which led to several reevaluations of the score $[10,11]$. TRISS combines the variables anatomic injury (ISS), physiological derangement (RTS), patient age, and injury mechanism to predict survival from trauma $[2,12]$. TRISS quickly became the standard method for outcome assessment $[12,13]$. For our analysis, we used the TRISS method with its coefficients published by Champion and colleagues in 1990 (MTOS 1990) [14].

Table 6 Variables of all scores.

\begin{tabular}{ccc}
\hline BIG Score & TRISS & PS09 Score \\
\hline BE & ISS & ISS \\
INR & Age & Age \\
GCS & Injury mechanism & GCS \\
& RTS & Gender \\
& & Intubation \\
\hline
\end{tabular}

BE: Base Excess; INR: International Normalized Ratio; GCS: Glasgow Coma Scale; ISS: Injury Severity Score; RTS: Revised Trauma Score.
The PS09 Score (Probability of Survival, Model: 09) In 2006, Bouamra and colleagues [19] published a new survival prediction model based on data from the UK Trauma Audit and Research Network (TARN). Since 1989, TARN used TRISS as a score to predict outcome, initially with the MTOS 1990 coefficients, and later with UK TARN-derived TRISS coefficients. However, with the TRISS method, a large amount of data was lost. In the PS09 model, the prediction-model coefficients have been revised on recent data; the model still includes all those subsets by using age, a transformation of ISS, GCS, gender, and Gender $\times$ Age interaction as predictors [9].

\section{Statistical analysis}

The statistical analysis of this study is based on the data from six civilian and one military database, extracting data from specified periods between 2005 and 2010 . Demographic data are presented as means with standard deviation (SD) for continuous variables and as percentages for incidence rates. The $U$ test was used for continuous variables, and the $\chi_{2}$ test for categoric variables. Statistical significance was set at $P$ values less than 0.05 . The quality of all scoring systems in predicting mortality was analyzed and presented in terms of discrimination and precision. Discrimination measures the ability of a scoring system to separate survivors from nonsurvivors. This was measured with the area under the receiver operating characteristic curves (AUROCs). The ROC curve summarizes the trade-off between sensitivity and specificity of a predictive score by using all score values as potential cut-off values. Its value varies between 0.5 (no discrimination) and 1.0 (perfect discrimination). AUROCs are presented with $95 \% \mathrm{CI}$, and differences between AUROC curves were evaluated by using a method derived by Hanley and colleagues [15]. In addition, the precision describes how well a score-based prognosis is able to meet the observed mortality rate. All statistical analyses were performed by using IBM SPSS 20 (IBM SPSS Inc, Chicago, IL, USA).

\section{Key messages}

- This study validated three mortality-predicting scores on a multicenter database with military and civilian data.

- The BIG score has been shown to predict mortality in pediatric trauma patients. Our analysis show that this score can also be used on a representative adult trauma population.

- In the present analysis, the BIG score was shown to perform well in predicting mortality in the penetrating trauma population versus the blunt trauma population. 
- The BIG score is based on information available shortly after admission.

- Mortality predicting scores that are quickly available in the Emergency Department can be a useful tool to include patients in acute care research studies.

\section{Abbreviations}

AIS: Abbreviated Injury Scale; AUROC: area under the receiver operating characteristic; BD: base deficit; BE: base excess; BIG: base excess: International normalized ratio: Glasgow coma scale; Cl: confidence interval; CNS: central nervous system; ED: emergency department; EMTRAS: Emergency Trauma Score; GCS: Glasgow Coma Scale; ICU: intensive care unit; INR: International Normalized Ratio; INTRN: International Trauma Research Network; ISS: Injury Severity Score; JTRR: Joint Theatre Trauma Registry; NISS: New Injury Severity Score; OHSU: Oregon Health \& Science University; PS: probability of survival; PT: prothrombin time; ROC: receiver operating characteristic; RTS: Revised Trauma Score; TARN: Trauma Audit and Research Network; tbi: traumatic brain injury; TR-DGU: TraumaRegister DGU of the German Trauma Society (DGU).

\section{Competing interests}

The authors declare that they have no competing interests.

\section{Authors' contributions}

TB contributed to study design, acquisition and interpretation of data, recording of paper and analyzing data. $\mathrm{PS}, \mathrm{KB}, \mathrm{MM}, \mathrm{MS}$, and $\mathrm{MB}$ conceived of the study, provided statistical advice on study design, and analyzed data. $R L, K B$, and $M M$ contributed to analysis and interpretation of data and revision of the article. All other authors contributed to data collection and to manuscript revision. All authors read and approved the final manuscript for publication.

\section{Authors' details}

'Department of Traumatology and Orthopedic Surgery, Cologne Merheim Medical Center (CMMC), University of Witten/ Herdecke, Ostmerheimer Str. 200, D-51109 Cologne, Germany. ${ }^{2}$ Department of Traumatology, Division of Critical Care, Oslo University Hospital Ulleval, Kirkeveien 166, 0407 Oslo, Norway. ${ }^{3}$ Department of Anesthesiology, Division of Emergency and Critical Care, Oslo University Hospital Ulleval, Kirkeveien 166, 0407 Oslo, Norway. ${ }^{4}$ Trauma Unit, Department of Surgery, Academic Medical Center, University of Amsterdam, Meibergdreef 9, 1105 AZ Amsterdam, The Netherlands. ${ }^{5}$ Department of Surgery, San Francisco General Hospital, University of California San Francisco (CA), Campus Box 0807, San Francisco CA 941430807, USA. ${ }^{6}$ Department of Surgery Division of Trauma, Critical Care \& Acute Care Surgery Oregon Health \& Science University 3181 SW Sam Jackson Park Road, Mail Code L611 Portland, OR 97239, USA. ${ }^{7}$ Department of Pediatrics, San Antonio Military Medical Center, 3551 Roger Brooke Drive, San Antonio, TX 78234, USA. ${ }^{8}$ Associate Professor of Pediatrics, Director, Translational Research Program Division of Pediatric Critical Care Washington University in St Louis, St Louis Children's Hospital, St Louis, MO, USA 63110 United States Institute for Surgical Research, Fort Sam Houston, Texas, USA 78234. ${ }^{9}$ Trauma Sciences, Bart's and the London School of Medicine and Dentistry, Queen Mary University of London, 4 Newark Street, London, E1 2AT, UK. ${ }^{10}$ On behalf of the International Trauma Research Network (INTRN).

Received: 20 December 2012 Accepted: 11 July 2013

Published: 11 July 2013

\section{References}

1. Borgman M, Maegele M, Wade CE, Blackbourne LH, Spinella PC: Pediatric trauma BIG score: predicting mortality in children after military and civilian trauma. Pediatrics 2011, 127:e892-e897.

2. Boyd CR: Evaluating trauma care: the TRISS method: Trauma Score and the Injury Severity Score. J Trauma 1987, 27:370-378.

3. Bouamra O, Wrotchford A, Hollis S, Vail A, Woodford M, Lecky F: A new approach to outcome prediction in trauma: a comparison with the TRISS model. J Trauma 2006, 61:701-710.

4. Champion HR, Sacco WJ, Copes WS, Gann DS, Gennarelli TA: A revision of the Trauma Score. J Trauma 1989, 29:623-629.
5. TARN: PS12 Calculations. [http://www.tarn.ac.uk/Content.aspx?c=1895].

6. Frith D, Goslings JC, Gaarder C, Maegele M, Cohen MJ, Allard S, Johansson PI, Stanworth S, Thiemermann C, Brohi K: Definition and drivers of acute traumatic coagulopathy: clinical and experimental investigations. J Thrombosis Haemost 2010, 8:1919-1925.

7. Stanworth SJ, Morris TP, Gaarder C, Goslings JC, Maegele M, Cohen MJ, König TC, Davenport R, Pittet J-F, Johansson PI, Allard S, Johnson T, Brohi K: Reappraising the concept of massive transfusion in trauma. Crit Care 2010, 14:R239.

8. Arbeitsgemeinschaft "Scoring" der Deutschen Gesellschaft fuer Unfallchirurgie (DGU). Das Traumaregister der Deutschen Gesellschaft fuer Unfallchirurgie. Unfallchirurg 1994, 97:230-237.

9. Bouamra O, Wrotchford A, Hollis S, Vail A, Woodford M, Lecky F: Outcome prediction in trauma. Injury 2006, 37:1092-1097.

10. Millham FH, LaMorte WW: Factors associated with mortality in trauma: re-evaluation of the TRISS method using the National Trauma Data Bank. J Trauma 2004, 56:1090-1096.

11. Gabbe BJ: TRISS: does it get better than this? Acad Emerg Med 2004, 11:181-186.

12. Chawda MN, Hildebrand F, Pape HC, Giannoudis PV: Predicting outcome after multiple trauma: which scoring system? Injury 2004, 35:347-358.

13. Senkowski CK, McKenney MG: Trauma scoring systems: a review. JACS 1999, 189:491-503.

14. Champion HR: The Major Trauma Outcome Study. JTrauma 1990, 30:1356-1365.

15. Hanley J, McNeil B: A method of comparing the areas under receiver operating characteristic curves derived from the same cases. Radiology 1983, 148:839-843.

16. Brohi K, Singh J, Heron M, Coats T: Acute traumatic coagulopathy. J Trauma 2003, 54:1127-1130.

17. Hess JR, Brohi K, Dutton RP, Hauser CJ, Holcomb JB, Kluger Y, MackwayJones K, Parr MJ, Rizoli SB, Yukioka T, Hoyt DB, Bouillon B: The coagulopathy of trauma: a review of mechanisms. J Trauma 2008, 65:748-754

18. Maegele M, Lefering R, Yucel N, Tjardes T, Rixen D, Paffrath T, Simanski C, Neugebauer E, Bouillon B: Early coagulopathy in multiple injury: an analysis from the German Trauma Registry on 8724 patients. Injuny 2007, 38:298-304.

19. Sauaia A: Epidemiology of trauma deaths: a reassessment. J Trauma 1995, 38:185-193.

20. Brohi K, Cohen MJ, Davenport RA: Acute coagulopathy of trauma: mechanism, identification and effect. Curr Opin Crit Care 2007, 680-685.

21. Mitra B, Cameron P, Mori A, Maini A, Fitzgerald M, Paul E, Street A: Early prediction of acute traumatic coagulopathy. Resuscitation 2011, 82:1208-1213.

22. Hoffmann M, Lefering R, Rueger JM, Kolb JP, Izbicki JR, Ruecker $H$, Rupprecht M, Lehmann W: Pupil evaluation in addition to Glasgow Coma Scale components in prediction of traumatic brain injury and mortality. Br J Surg 2012, 99(Suppl 1):122-130.

23. Teasdale G: Adding up the Glasgow Coma Score. Acta Neurochir Supp/ 1979, 28:13-16.

24. Duncan R, Thakore S: Decreased Glasgow Coma Scale score does not mandate endotracheal intubation in the emergency department. JEmerg Med 2009, 37:451-455.

25. Green SM: Cheerio, laddie! Bidding farewell to the Glasgow Coma Scale. Ann Emerg Med 2011, 58:427-430.

26. Davis JW, Parks SN, Kaups KL, Gladen HEO'd-NS: Admission base deficit predicts transfusion requirements and risk of complications. J Trauma 1996, 41:769-774.

27. Mizushima Y, Ueno M, Watanabe H, Ishikawa K, Matsuoka T: Discrepancy between heart rate and makers of hypoperfusion is. 2011, 71:789-792.

28. Brohi K, Cohen MJ, Ganter MT, Matthay M, Mackersie RC, Pittet J-F: Acute traumatic coagulopathy: initiated by hypoperfusion: modulated through the protein C pathway? Ann Surg 2007, 245:812-818.

29. Tremblay LN, Feliciano DVRG: Assessment of initial base deficit as a predictor of outcome: mechanism of injury does make a difference. Am Surgeon 2002, 68:689-693.

30. Hodgman El, Morse BC, Dente CJ, Mina MJ, Shaz BH, Nicholas JM, Wyrzykowski AD, Salomone JP, Rozycki GS, Feliciano DV: Base deficit as a marker of survival after traumatic injury: consistent across changing patient populations and resuscitation paradigms. I Trauma Acute Care Surg 2012, 72:844-851. 
31. Rixen D, Raum M, Bouillon B, Lefering R, Neugebauer $E$,

Arbeitsgemeinschaft "Polytrauma" of the Deutsche Gesellschaft fur

Unfallchirurgie": Base deficit development and its prognostic significance

in posttrauma critical illness: an analysis by the trauma registry of the

Deutsche Gesellschaft für Unfallchirurige. Shock 2001, 15:83-89.

32. Raum MR, Nijsten MWN, Vogelzang M, Schuring F, Lefering R, Bouillon B,

Rixen D, Neugebauer E, Ten Duis HJ: Emergency trauma score: an

instrument for early estimation of trauma severity. Crit Care Med 2009,

37:1972-1977.

33. Perel P, Prieto-Merino D, Shakur H, Clayton T, Lecky F, Bouamra O, Russell $R$ Faulkner M, Steyerberg EW, Roberts I: Predicting early death in patients with traumatic bleeding: development and validation of prognostic model. BMJ 2012, 345:e5166-e5166.

doi:10.1186/cc12813

Cite this article as: Brockamp et al: Comparison of the predictive performance of the BIG, TRISS, and PS09 score in an adult trauma population derived from multiple international trauma registries. Critical Care 2013 17:R134

\section{Submit your next manuscript to BioMed Central} and take full advantage of:

- Convenient online submission

- Thorough peer review

- No space constraints or color figure charges

- Immediate publication on acceptance

- Inclusion in PubMed, CAS, Scopus and Google Scholar

- Research which is freely available for redistribution

Submit your manuscript at www.biomedcentral.com/submit
Ciomed Central 